\title{
Coexpression of Two Fibronectin Receptors, VLA-4 and VLA-5, by Immature Human Erythroblastic Precursor Cells
}

\author{
M. Rosemblatt, M. H. Vuillet-Gaugler, C. Leroy, and L. Coulombel \\ Laboratoire d'Hématologie, Hôpital de Bicêtre, 94270 Le Kremlin-Bicêtre, France
}

\begin{abstract}
Human erythroblastic precursor cells adhere to fibronectin (Fn) but the exact nature of the receptors mediating this interaction has not been characterized. In this study, we report data showing that immature human erythroblasts express the integrins VLA-4 and VLA-5 and that both these molecules act as fibronectin receptors on these cells. We have recently demonstrated that adhesion to Fn of purified human CFU-E and their immediate progeny preproerythroblasts was inhibited by antibodies directed against the human fibronectin receptor (VLA5). Here we have extended those results and characterized by immunoprecipitation with specific antibodies the integrins expressed on surface-labeled normal human immature erythroblasts. A polyclonal antibody recognizing the common VLA $\beta 1$ subunit yielded two polypeptides of 120 and $160 \mathrm{kD}$. Our data further demonstrate that the polypeptide of $160 \mathrm{kD}$ contains $\alpha$ subunits corresponding to both $\alpha 4$ and $\alpha 5$. Thus, erythroblast lysates prepared in $0.3 \%$ CHAPS and immunoprecipitated with antibodies which specifically recognize the $\alpha 4$ subunit showed a heterodimer with peptides of $120(\beta 1)$ and $160 \mathrm{kD}(\alpha 4)$ and the additional peptides of 70 and $80 \mathrm{kD}$ which usually coprecipitate with the $\alpha 4$ chain. On the other hand, specific anti- $\alpha 5$ antibodies immunoprecipitated an $\alpha 5 / \beta 1$ complex with peptides of 120 and $160 \mathrm{kD}$ which under reducing conditions migrated as a single band of $130 \mathrm{kD}$. Similar experiments performed with an erythroleukemic cell line (KU 812) showed that these cells also coexpress both the VLA- 4 and VLA- 5 members of the integrin family. Furthermore, monoclonal antibodies recognizing the VLA $\alpha \mathbf{4}$ chain blocked the adhesion of immature erythroblasts to Fn-coated surfaces, thus demonstrating that, as VLA-5, VLA-4 is also a functional Fn receptor on these cells. (J. Clin. Invest. 1991. 87:6-11.) Key words: integrins • adhesion • fibronectin • differentiation • erythroblasts
\end{abstract}

These results were presented in part at the UCLA Symposium on Molecular Basis of Cell Adhesion in January 1990 and published in an abstract form. (1990. J. Cell. Biochem. Suppl. 14A. Abstr. 205).

Address all correspondence to Dr. Laure Coulombel, Institut de Pathologie Cellulaire, Hôpital de Bicêtre, 94270 Le Kremlin-Bicêtre, France.

M. Rosemblatt is on sabbatical leave from INTA, Universidad de Chile, Santiago, Chile.

Received for publication 15 March 1990 and in revised form 9 July 1990.

J. Clin. Invest.

(c) The American Society for Clinical Investigation, Inc. $0021-9738 / 91 / 01 / 0006 / 06 \quad \$ 2.00$

Volume 87, January 1991, 6-11

\section{Introduction}

Cell adhesion to fibronectin (Fn) ${ }^{1}$-containing matrices appears as an essential mechanism in the control of normal cell differentiation as well as in cancer cell metastasis (1-4). These interactions occur through specific cell surface receptors, some of which belong to the VLA group of the integrin superfamily. VLA proteins include at least six heterodimers composed of a distinct $\alpha$ subunit noncovalently associated with a common $\beta 1$ subunit of $120-130 \mathrm{kD}(5,6)$. At least three of these glycoproteins (VLA-3, VLA-4, and VLA-5) can bind Fn (7-10). Both VLA-3 and VLA-5 contain $\alpha$ chains of $160 \mathrm{kD}$ under nonreducing conditions but which migrate as a $130-\mathrm{kD}$ polypeptide under reducing conditions (5). The VLA- $4 \alpha$ subunit also migrates on nonreducing polyacrylamide gels as a $160-\mathrm{kD}$ polypeptide but reduction does not alter its migration (8). Although these three receptors bind to Fn, they are not functionally identical. Thus, VLA-5 and VLA-3 bind specifically to the Arg-GlyASP-ser (RGDS) sequence of Fn $(11,12)$, whereas recent studies suggest that VLA-4 acts as a receptor for the CS-1 region of this molecule (13). In contrast to VLA-5 which functions exclusively as a Fn receptor, both VLA-3 and VLA-4 have multiple ligands: VLA-3 binds Fn, laminin and collagen depending on the cell type (9), and VLA-4 recognizes ligand molecules expressed on endothelial cells different from Fn (14, 15). Cell distribution for each one of these integrins shows a clearly distinct pattern. Thus, VLA-5 is widely distributed $(5,8,16)$, whereas the expression of VLA-3 and VLA-4 is more restricted, the first to adherent cells such as fibroblasts and epithelial cells $(5,17)$, and the second to peripheral blood cells of the monocytic and lymphoid lineages as well as related cell lines $(13,16,18)$.

In contrast to the extensive characterization of extracellular matrix receptors on mature peripheral blood cells, nothing is known on integrin expression at earlier stages of hematopoietic differentiation. This laboratory as well as others has recently

' provided evidence for the existence of Fn adhesion during human and murine erythropoietic differentiation (19-21). However, the lack of a reproducible procedure to purify erythroid progenitor cells has prevented the direct characterization of integrins on these human cells.

We have recently reported a procedure to obtain highly purified CFU-E and preproerythroblasts from human marrow, and we have shown that these cells selectively attach to Fn and lose this property during terminal erythroid differentiation

1. Abbreviations used in this paper: CFU-E, colony forming unit erythroid; CHAPS, (3-[3-(cholamidopropyl)-dimethylammonio]-1 propanesulfonate); $\mathrm{Fn}$, fibronectin. 
(22). The involvement of VLA-5 as a functional Fn-receptor was indirectly supported by the observation that an anti-VLA5 MAb blocked attachment of both CFU-E and preproerythroblasts to Fn (22).

In this report, we demonstrate that two molecules of the VLA family, VLA-4 and VLA-5, can be immunoprecipitated from the cell surface of these immature human erythroblasts as well as from the cell surface of the human erythroleukemic cell line KU 812. Furthermore, monoclonal antibodies directed against the $\alpha 4$ subunit also blocked adhesion of these immature erythroblasts to $\mathrm{Fn}$, thus demonstrating that in addition to VLA-5, VLA-4 also functions as a Fn receptor on these cells.

\section{Methods}

Source of human erythroblastic cells. Immature erythroblasts were purified as a homogeneous population from normal human marrow by negative selection using an avidin-biotin immune rosetting procedure as previously described (21). The purified population, which is reproducibly $>80 \%$ erythroblastic by immunologic labeling with anti-CD 36 antibody (23) has been extensively characterized by colony assays and electron microscopy (22). It includes two erythroid cell types: 10 $15 \%$ CFU-E, and $60-70 \%$ preproerythroblasts. A CFU-E is defined by its capacity to generate in semi-solid assays a colony of 10-100 hemoglobinized erythroblasts at day 8-10, whereas preproerythroblasts, which represent the immediate progeny of CFU-E, are identified by ultrastructural features and form only small lytic colonies in vitro. Thus, even though CFU-E and preproerythroblasts cannot be independently purified, their properties can be separately assessed. These cells were incubated overnight at $37^{\circ}$, in an air atmosphere supplemented with $5 \% \mathrm{CO}_{2}$ in alpha medium supplemented with $20 \%$ FCS and 3 $\mathrm{U} / \mathrm{ml}$ of erythropoietin (a kind donation of Dr. C. Eaves, Terry Fox Laboratory, Vancouver, Canada) before they were surface labeled (see below). The erythroleukemic cell lines K-562, KU 812, and the T lymphoid cell line MOLT-4 were cultured in RPMI 1640 supplemented with $10 \%$ FCS. The KU 812 cell clone used in this study was obtained from Dr. W. Vainchenker (INSERM U 91, Hôpital H. Mondor, Créteil, France) and has been derived from the initial cell line generated by $\mathrm{K}$. Kishi $(24,25)$.

Antibodies against integrin receptors. Protein A purified rabbit polyclonal IgG raised against the human placental fibronectin receptor (anti-FnR) was purchased from Telios Pharmaceuticals (San Diego, CA). This antibody reacts mainly with the common integrin $\beta 1$ subunit of the VLA family (26). Mouse MAbs B5-G10 and HP2/1 directed against the extracellular domain of the $\alpha 4$ subunit of VLA-4 were kindly obtained from Dr. M. E. Hemler (Dana-Farber Cancer Institute, Boston, MA) (8) and Dr. F. Sanchez-Madrid (Hospital de la Princesa, Madrid, Spain), respectively (27). MAb TS2/16 against the $\beta 1$ subunit was a gift of Dr. F. Sanchez-Madrid (28). BIE5, a rat MAb specific for the $\alpha 5$ subunit of VLA- 5 was a kind gift of Dr. C. Damsky (University of California, San Francisco, CA) (29). Affinity purified polyclonal IgG (33.8) directed against the cytoplasmic domain of the $\alpha 5$ subunit (30) were kindly provided by Dr. J. A. McDonald (Washington University School of Medicine, St. Louis, MO). Two monoclonal antibodies directed against the $\alpha 3$ subunit of VLA-3 were used: J 143 a kind gift of Dr. A. Albino (31), and P1 B5 (32) purchased from Telios Pharmaceuticals. Among these antibodies, only HP 2/1, B1E5, and P1B5 have the property to inhibit cell adhesion to fibronectin, whereas B5G10, TS2/ $16,33.8$, and $\mathrm{J} 143$ recognize integrin epitopes which are not involved in ligand binding.

Cell adhesion and antibody inhibition assays. Attachment of erythroid precursor cells to Fn was assessed as previously described (18). Briefly, 2-4 $\times 10^{5}$ purified cells were incubated for $2 \mathrm{~h}$ at $37^{\circ}$ in a $5 \%$ $\mathrm{CO}_{2}$ atmosphere on $2 \mathrm{~cm}^{2}$ Fn-coated tissue culture wells. After the removal of nonadherent cells, the wells were gently washed twice and the adherent cells detached by a mild trypsin treatment. Both adherent and nonadherent cell populations were counted and plated in methylcellulose colony-assays to assess the number of erythroid progenitor cells CFU-E as previously described in detail (19). As preproerythroblasts represent $60-70 \%$ of the purified population, we estimated their number to be close to the number of nucleated cells (22). To test the effect of the various antibodies on cell adhesion to $F n$, cells were preincubated with the selected antibodies for $1 \mathrm{~h}$ at $4^{\circ}$, and the attachment assay was then performed in the continuous presence of the antibody as described above. B1E5 and HP 2/1 were used as undiluted hybridoma supernatants, P1B5 as a 1/100 dilution of ascitic fluid, and the polyclonal anti-Fn receptor antibody at a $1 / 10$ dilution. Control antibodies included: nonimmune IgG, MAb FA6152, which recognizes a 78-88 kD glycoprotein on erythroblasts, monocytes, and platelets (33), and MAbs B5G10 and TS2/16 which recognize integrin epitopes not involved in fibronectin adhesion.

Labeling and immunoprecipitation of cell surface integrins. Cells $\left(2-10 \times 10^{6}\right)$ were surface-labeled with $1 \mathrm{mCi}$ of ${ }^{125} \mathrm{I}$ using the lactoperoxidase method. Cell lysates were initially prepared by incubating the cells for $30 \mathrm{~min}$ at $4^{\circ} \mathrm{C}$ in $1 \%$ Triton $\mathrm{X}-100$, but in subsequent experiments $0.3 \%$ CHAPS was prefered to avoid dissociation of the $\alpha 4 \beta 1$ complex $(8,13)$. Both detergents were prepared in HBSS containing 1 $\mathrm{mM} \mathrm{CaCl} 2$ and $0.5 \mathrm{mM} \mathrm{MgCl}$ with freshly added $2.0 \mathrm{mM}$ phenylmethyl sulfonyl fluoride and $10 \mu \mathrm{g} / \mathrm{ml}$ of aprotinin (lysis buffer). After centrifugation of the cell lysates at $10,000 \mathrm{~g}$ for $15 \mathrm{~min}$ at $4^{\circ} \mathrm{C}$ the supernatants were dialyzed against lysis buffer without aprotinin and precleared with normal rabbit serum and Protein A-Sepharose. Immunoprecipitations with specific antibodies were done as described elsewhere (5). Bound antigens were dissociated by boiling for $5 \mathrm{~min}$ in SDS sample buffer without reducing agent (34). In those experiments in which the antigens were analyzed both under reducing and nonreducing conditions the collected supernatants were divided into two identical aliquots, $\beta$ mercapto-ethanol (3\%) added to one of them and both reheated at $100^{\circ} \mathrm{C}$ for $3 \mathrm{~min}$. Solubilized antigens were analyzed by PAGE in $7.5 \%$ gels as described by Laemmli (34) and specific bands revealed by autoradiography. A mixture of proteins of known molecular weights (Bio-Rad Laboratories, Richmond, CA) was included in each gel to estimate the relative size of the unknown peptides.

Immunofluorescence staining. Indirect immunofluorescent staining of unfixed purified erythroblastic cells with HP 2/1, B1E5, and J143 was done in suspension (22). Control experiments done with irrelevant antibodies gave no significant fluorescence.

\section{Results}

Identification of VLA molecules expressed on normal human erythroid precursors and in the erythroleukemic cell line $K U$ 812. To identify the integrins expressed by normal human erythroblastic precursors, we first immunoprecipitated lysates of these cells prepared in $0.3 \%$ CHAPS with a polyclonal antibody prepared against the Fn receptor from human placenta. This antibody coprecipitates the $\beta 1$ subunit together with the corresponding noncovalently associated $\alpha$ chains. Two bands of 120 and $160 \mathrm{kD}$ (Fig. 1 a) corresponding to the $\beta 1$ subunit and to one or more VLA $\alpha$ subunits, respectively, were detected on polyacrylamide gels. In cell lysates done with $1 \%$ Triton X-100 the $120-\mathrm{kD}$ band was predominant, little or none of the $\alpha$ subunit could be detected, indicating that partial dissociation of the $\alpha \beta 1$ complex occured with this detergent (data not shown). To further identify the $\alpha$ subunits coprecipitating with the $\beta 1$ polypeptide we immunoprecipitated CHAPS lysates of erythroblasts with the anti- $\alpha 4$ MAb B5-G10 and with the anti- $\alpha 5$ MAb B1E5. With both antibodies we observed two bands of 120 and $160 \mathrm{kD}$ under nonreducing conditions (Fig. 


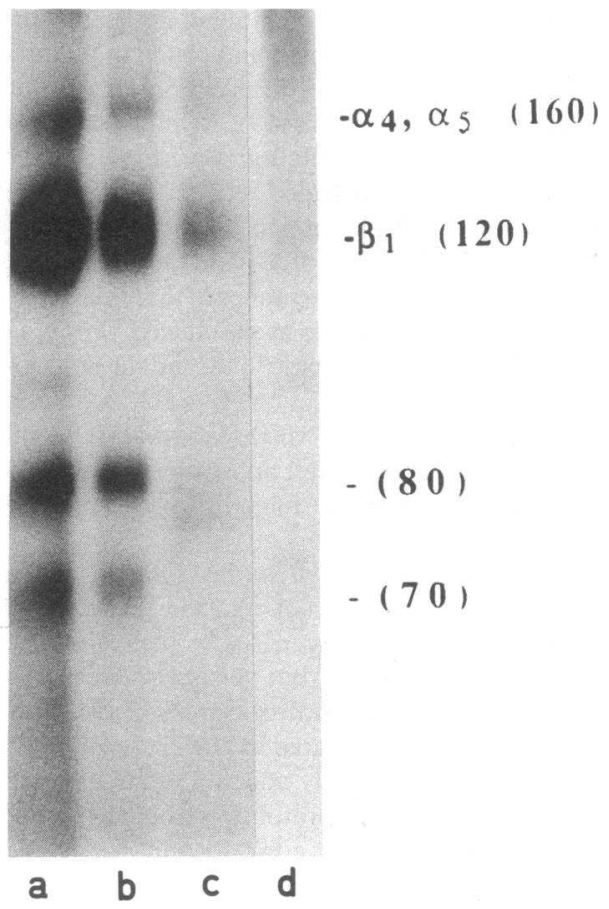

Figure 1. Immunoprecipitation of integrin complexes from normal human erythroblasts. Lysates from ${ }^{125}$ I surface-labeled erythroblasts were prepared in $0.3 \%$ CHAPS and incubated with an anti-human Fn receptor antibody (lane $a$ ), with anti- $\alpha 4$ MAb B5-G10 (lane $b$ ), with the anti- $\alpha 5$ MAb B1E5 (lane $c$ ), or with the anti- $\alpha 3$ J143 MAb (lane $d$ ). The immune complexes were collected by adsorption on Protein A-Sepharose and analyzed by SDS-PAGE under nonreducing conditions on $7.5 \%$ gels followed by autoradiography. Control immunoprecipitations were done under identical conditions with normal rabbit serum and showed no bands (not shown). The different $\alpha$ subunits expressed by these cells were identified by antibody recognition and size and by the presence of bands at 70 and $80 \mathrm{kD}$. Molecular weights of immunoprecipitated proteins were determined based on the migration of markers of known molecular weight.

$1, b$ and $c$ ) indicating that both $\alpha 4$ and $\alpha 5$ subunits were expressed on these cells. Similar results were obtained when cell lysates were immunoprecipitated with the MAb HP 2/1, or with $\mathrm{Ab} 33.8$, a rabbit antibody that recognizes a small peptide present in the cytoplasmic domain of $\alpha 5$ (30) (data not shown). Immunoprecipitates done either with the polyclonal antifibronectin receptor antibody or with the anti- $\alpha 4 \mathrm{MAb}$ contained additional bands of 70 and $80 \mathrm{kD}$ characteristic of $\alpha 4$ containing lysates (Fig. $1, a$ and $b)(8,13)$. No bands were detected on gels from erythroblast lysates immunoprecipitated with the anti- $\alpha 3$ mAbs J143 and P1B5 (Fig. $1 d$ ).

K 562 cells have been reported to express only VLA- 5 and to lack VLA-4 $(5,13)$, a result that we have confirmed (data not shown). To investigate further if the difference in the expression of the VLA-4 integrin between erythroleukemic cells and their normal counterparts was a general property of transformed erythroid cells, we studied the expression of VLA-4 and VLA-5 on another erythroleukemic cell line, KU 812. These cells, which bind selectively to Fn (Leroy, C., M. Rosemblatt, and L. Coulombel, unpublished results) express several erythroid markers such as adult hemoglobin, glycophorin $\mathrm{A}$ and $\mathrm{C}$, carbonic anhydrase 1 , and CD 36 (25). Fig. 2 shows that gels of Triton-X100 lysates of surface-labeled KU-812 cells immunoprecipitated with the polyclonal antifibronectin receptor antibody exhibited two bands of 120 and $160 \mathrm{kD}$ under nonreduced conditions (Fig. 2 a). Under reducing conditions also two bands were observed of 130 and $160 \mathrm{kD}$ (Fig. $2 e$ ). Immunoprecipitation of an identical lysate with the anti- $\alpha 5 \mathrm{MAb}$ B1E5 yielded two bands of 120 and $160 \mathrm{kD}$ under nonreducing conditions (Fig. 2 c) but only a single band of $130 \mathrm{kD}$ on a reducing gel (Fig. $2 \mathrm{~g}$ ) a pattern characteristic of the nonreduced and reduced forms of the $\beta 1$ and the $\alpha 5$ chains of VLA5 . The presence of a band of $160 \mathrm{kD}$ on reducing gels of lysates immunoprecipitated with the anti- $\beta 1$ antibody indicated the presence of another $\alpha$ chain in the lysate besides $\alpha 5$. This extra band corresponded to the $\alpha 4$ subunit on the following arguments: $(i)$ specific anti- $\alpha 4$ antibody B5-G10 immunoprecipitated both $\alpha 4$ and $\beta 1$ chains from CHAPS lysates of KU 812 (Fig. 2, $b$ and $f$ ); (ii) two bands at 70 and $80 \mathrm{kD}$ characteristic of VLA-4 $(8,13)$ were present on these gels (see Fig. 2, $a, b, e$, and $f$ ) and (iii) preclearing of a Triton-X 100 lysate of KU 812 with MAb B1E5 removed all $\alpha 5$ reactivity (Fig. $2 h$ ) but left residual proteins that could be precipitated by the anti- $\alpha 4$ antibody HP2/1 (Fig. $2 i$ ). Similar to the results found with normal erythroblasts, $\alpha 3$ could not be immunoprecipitated from KU 812 cells (Fig. $2 d$ ). Differences in the expression of integrins between K 562 and KU 812 erythroleukemic cell lines is a further illustration of the phenotypic heterogeneity of cell lines.

Immunofluorescence experiments confirmed that close to $100 \%$ of KU 812 cells and purified erythroblasts stained brightly with the anti- $\alpha 4$ mAb HP 2/1. Similar results were obtained with the MAb B1E5 on KU 812 cells, but staining of normal erythroblasts with this MAb was not different from background, suggesting that, in contrast to $\alpha 4$, only low numbers of $\alpha 5$ are expressed on normal erythroblasts (not shown). $\alpha 3$ was not detectable by immunofluorescence neither on $\mathrm{KU}$ 812 cells nor on normal erythroblasts.

Inhibition of the adhesion to fibronectin of normal erythroblasts by anti-VLA-4 antibody. In recent studies, we demonstrated that purified CFU-E and preproerythroblasts adhere selectively to Fn-coated substrates in the proportion of 58 and $31 \%$, respectively, but failed to adhere to laminin and collagens type I and III. We further demonstrated that Fn attachment was inhibited by a polyclonal antifibronectin receptor and the anti- $\alpha 5$ MAb B1E5 (22). Results obtained in this study on six separate experiments confirmed the inhibitory effect of the anti- $\alpha 5$ antibody (Fig. 3). Interestingly, whereas B1E5 blocked $85 \%$ of CFU-E attachment to Fn, it inhibited only $70 \%$ of preproerythroblasts adhesion to Fn. To determine if VLA-4 also mediates adhesion to Fn on these cells, we labeled purified erythroid cells (CFU-E + preproerythroblasts) with HP 2/1 and incubated them on Fn-coated dishes. Shown on Fig. 3 are the results of nine independent experiments; preincubation of cells with this anti- $\alpha 4$ MAb inhibited both CFU-E and preproerythroblasts attachment to Fn at least by $70 \%$, thus indicating that VLA-4 is also a functional Fn receptor on erythroblasts. When cells were incubated in the same experiments with a mixture of both B1E5 and HP 2/1, adhesion of CFU-E and preproerythroblasts was inhibited to a greater extent $(95 \%)$ than in the presence of each Ab separately (Fig. 3), a result which suggests that the effect of VLA-4 and VLA- 5 in the attachment of erythroblastic cells to Fn might be complementary. Neither B1E5 nor HP 2/1 were cytotoxic for erythroid 


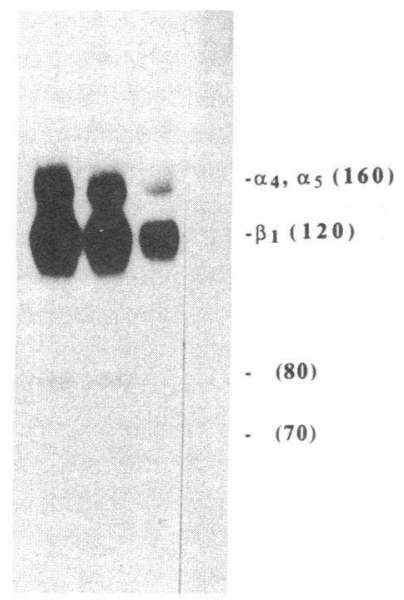

a b c d

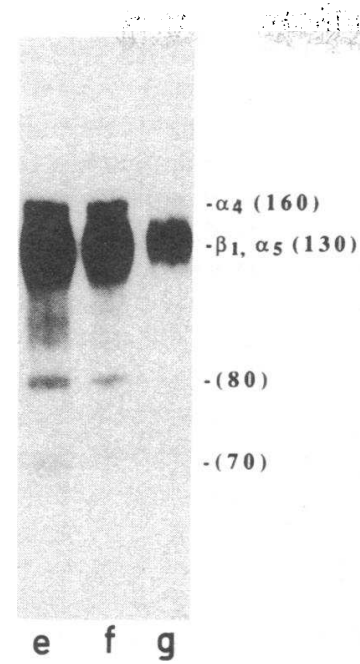

Figure 2. Immunoprecipitation of integrin complexes from KU 812 cells. Lysates prepared from ${ }^{125} \mathrm{I}$ surface-labeled KU 812 cells were immunoprecipitated with an anti-human Fn receptor antibody (lanes $a$ and $e$ ), with anti- $\alpha 4$ MAb B5-G10 (lanes $b$ and $f$ ), with the anti- $\alpha 5$ MAb B1E5 (lanes $c$ and $g$ ), or with anti- $\alpha 3$ MAb J 143 (lane $d$ ). The immune complexes were precipitated with Protein A-Sepharose and analyzed by SDS-PAGE under nonreducing conditions (lanes $a-d$ ) or under reducing conditions (lanes $e-g$ ) on $7.5 \%$ gels followed by autoradiography. Control immunoprecipitations were done under identical conditions with normal rabbit serum and showed no bands (not shown). On lanes $h$ and $i$, a lysate of ${ }^{125}$ I surface-labeled KU 812 cells was precleared by three cycles of immunoprecipitation with the anti- $\alpha 5$ MAb BIE5 followed by incubation with anti- $\alpha 5$ antibody B1E5 (lane $h$ ) or with the anti- $\alpha 4$ antibody HP 2/1 (lane $i$ ). Immunoprecipitates were analyzed by SDS-PAGE

under nonreducing conditions (7.5\%) followed by autoradiography. Molecular weights of immunoprecipitated proteins were determined based on the migration of markers of known molecular weight.

cells, and none of the control antibodies inhibited adhesion to fibronectin. The MAb P1B5, which has been shown to inhibit fibroblast adhesion to Fn by blocking VLA-3 binding (32) failed to inhibit erythroblasts adhesion to fibronectin.

\section{Discussion}

Attachment to ECM components through the integrin cell-surface receptors is one of the mechanisms by which cells regulate a number of their biological functions such as proliferation, differentiation, and migration (1-4). That such a mechanism is also operative during erythropoietic differentiation is suggested by recent results from this (19) and other (21) laboratories showing that normal immature progenitors CFU-E and their immediate progeny preproerythroblasts adhere specifically to Fn-coated dishes but not to other ECM molecules such as laminin or collagen types I, III, and IV. In this study, we provide evidence that these immature normal erythroblast precursors express two integrins, VLA-4 and VLA-5, and that both mediate cell binding to Fn.

The molecular characterization of integrins expressed on primitive normal hematopoietic progenitor cells from human marrow has been hampered by the difficulty to purify these populations. The usual alternative approach has been to work with phenotypically related cell lines, and most of the data on integrin expression in hematopoietic cells have been generated through the use of such models $(5,8,18)$. Thus, VLA-4 and VLA-5 are coexpressed by a number of myeloid, monocytic, and lymphoid cell lines, whereas it has been claimed, based on data obtained with K 562 erythroleukemic cells, that VLA-5 was the only integrin detectable on cells of erythroid origin (5, 13). Results obtained in this study both by immunoprecipitation and immunofluorescence clearly show that another erythroleukemic cell line, KU 812, expresses high amounts not only of VLA-5, but also of VLA-4. Such a heterogeneity in the expression of cell surface integrins among cell lines of related phenotype, together with the previously reported modulation of these molecules by culture conditions (35) should be taken into account when such models are used to understand the physiological significance of integrin expression during normal human erythroid differentiation.

We have recently described a procedure that permits the purification from normal human marrow of a homogeneous population of very immature erythroblasts including 10-15\% CFU-E and $60-70 \%$ preproerythroblasts (which represent the immediate progeny of CFU-E) in numbers sufficient to per-

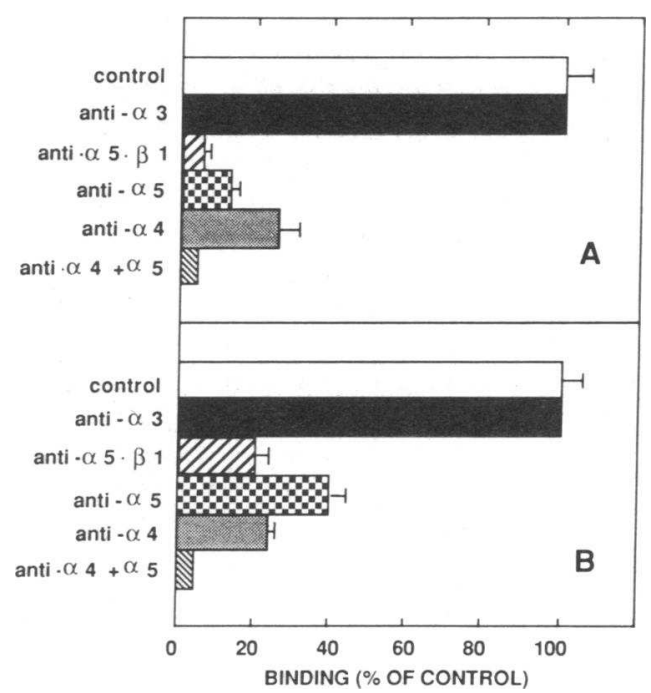

Figure 3. Inhibition of CFU-E and preproerythroblasts adhesion to fibronectin by anti-VLA antibodies. Purified erythroblastic cells were preincubated with the following antibodies: anti- $\alpha 3$ (P1B5); $n=1$. Polyclonal anti- $\alpha 5 \beta 1$ (human placenta Fn receptor), $n=6$. Anti $\alpha 5$ (BIE5), $n=6$. Anti- $\alpha 4$ (HP2/1), $n=9$. Anti- $\alpha 5$ (BIE5) + anti- $\alpha 4$ (HP2/1), $n=2$. Adhesion was then performed during 90 min on 20 $\mu \mathrm{g} / \mathrm{ml}$ fibronectin-coated wells. Controls included antibodies directed against integrins epitopes not involved in Fn binding (see Methods). Histograms show the mean \pm SEM of at least three experiments and are expressed relative to the specific adhesion to $\mathrm{Fn}$ in the absence of any antibody (100\%). $A$ shows the results obtained with CFU-E cells, whereas $B$ shows those obtained with the purified population (CFU-E + preproerythroblasts). 
form biochemical studies (22). These cells bind selectively to Fn-coated dishes and this process was inhibited by MAb B1E5 (anti- $\alpha 5)$, strongly suggesting that VLA-5 was expressed on these cells. Immunoprecipitation of surface-labeled purified erythroblasts with MAb B1E5 (Fig. $1 c$ ) and the polyclonal anti- $\alpha 5$ antibody 33.8 (not shown) revealed that the erythroblastic VLA-5 $\alpha$ chain had the expected molecular weight of $150 \mathrm{kD}$ unreduced and $130 \mathrm{kD}$ reduced, and is very similar if not identical to the fibroblast fibronectin receptor. More surprisingly, reducing gels from cell lysates immunoprecipitated with an anti- $\beta 1 \mathrm{Ab}$ (not shown) revealed the presence of another $\alpha$ chain besides $\alpha 5$. Identification of this second integrin as VLA-4 was directly demonstrated by immunoprecipitating this receptor with a specific anti- $\alpha \mathbf{M A b}$, and indirectly by two additional observations. First, all immunoprecipitates done with the polyclonal anti-Fn receptor antibody or with MAb B5-G10 revealed two bands at 70 and $80 \mathrm{kD}$ which are specifically associated with $\alpha 4$ but not with the other VLA molecules $(8,13)$ and second, as reported by others $(8,13)$, we also found that the $160-\mathrm{kD}$ band corresponding to the $\alpha 4$ chain was absent or barely visible from gels of immunoprecipitates of erythroblasts lysates prepared in 1\% Triton-X100 (data not shown).

In contrast to VLA-4 and VLA-5, VLA-3, which functions also as a Fn receptor and has subunit molecular weights similar to those of VLA-5 (10) could not be demonstrated neither on immature erythroblasts nor on KU 812 cells by immunofluorescence, immunoprecipitation, or adhesion inhibition with the anti- $\alpha 3$ MAbs. This is in agreement with the usual lack of expression of this integrin on cells growing in suspension (36).

VLA-5 is widely distributed and binds to the RGD sequence of the Fn cell binding domain, whereas VLA-4, which has been identified only on murine and human lymphoid and granulocytic cells $(13,37)$, recognizes the $\mathrm{COOH}$-terminal 10 amino acids of the alternatively spliced $\mathrm{V}$ segment of the Fn molecule (CS-1) $(13,38)$. In addition to Fn, VLA-4 has other ligands: it is involved in homotypic cell-cell interaction (39) and lymphocyte homing (14), and recognizes VCAM-1, a molecule expressed by cytokine-activated human endothelial cells (15). Our antibody inhibition experiments demonstrate that cell attachment to Fn through VLA-4 is not restricted to lymphoid cells because it also characterizes normal human immature erythroblasts and therefore might be a more widely expressed molecule in the hematopoietic system. Whether or not the VLA-4 present on erythroblasts also recognizes the CS-1 domain of Fn remains to be determined.

The biological significance of the expression by erythroblastic cells of two distinct integrins probably binding to different attachment sites on the fibronectin molecule is unclear. Partial inhibition of cell adhesion obtained with the $\alpha 4 \beta 1$ and the $\alpha 5 \beta 1$ antibodies separately and their additive effect when used in combination (see Fig. 3) suggest that both receptors can function independently but cooperate in mediating erythroblast adhesion to fibronectin, an hypothesis which agrees with results obtained by several groups using non erythroid cells (40-42). In vivo both integrins might be independently regulated during normal erythroid differentiation, thus affecting erythroblasts interactions with their marrow environment. This is suggested by our previous observations that adhesion to Fn first increases during early stages of erythroid differentiation, and is subsequently lost with terminal maturation $(19,22)$.

\section{Acknowledgments}

The authors would like to acknowledge Drs. A. Albino, C. Damsky, M. Hemler, J. McDonald, and F. Sanchez-Madrid, for their generous gifts of the anti-integrin antibodies used in this study. We also thank Dr. C. J. Eaves for her gift of erythropoietin, Drs. Brunet, Lapresle, Missenard (clinique Arago), Bonnet, and Koechlin (Hôpital Croix-Rouge) for providing marrow samples; and R. Berthier, JP. Fermand for their gift of antibodies used in the purification of erythroblasts. This work was supported by grants from INSERM (LC-CRE 862007), Association pour La Recherche sur Le cancer (ARC) (LC-6532), and University Paris XI. M. H. Gaugler and M. Rosemblatt are recipients of fellowships from ARC.

\section{References}

1. Yamada, K. 1983. Cell surface interaction with extracellular material. Annu. Rev. Biochem. 52:761-799.

2. Boucaut, J. C., T. Darribère, T. J. Poole, H. Aoyama, K. M. Yamada, and J. P. Thiery. 1984. Biologically active synthetic peptides as probes of embryonic development: a competitive peptide inhibitor of fbronectin function inhibits gastrulation in amphibious embryos and neural crest cell migration in avian embryos. J. Cell Biol. 99:1822-1830.

3. Menko, A. S., and D. Boettiger. 1987. Occupation of the extracellular matrix receptor integrin is a control point for myogenic differentiation. Cell. 51:51-57.

4. Plantefaber, L. C., and R. O. Hynes. 1989. Changes in integrin receptors on oncogenically transformed cells. Cell. 56:281-290.

5. Hemler, M. E., C. Huang, and L. Schwarz. 1987. The VLA protein family. Characterization of five distinct cell surface heterodimers each with a common 130,000 molecular weight $\beta$ subunit. J. Biol. Chem. 262:3300-3309.

6. Ruoslahti, E., and M. D. Pierschbacher. 1987. New perspectives in cell adhesion: RGD and integrins. Science (Wash. DC). 238:491-497.

7. Pytela, R., M. D. Pierschbacher, and E. Ruoslahti. 1985. Identification and isolation of a $140 \mathrm{kd}$ cell surface glycoprotein with properties expected of a fibronectin receptor. Cell. 40:191-198.

8. Hemler, M. E., C. Huang, Y. Takada, L. Schwarz, J. L. Strominger, and M. L. Clabby. 1987. Characterization of the cell surface heterodimer VLA-4 and related peptides. J. Biol. Chem. 262:11478-11485.

9. Wayner, E. A., and W. G. Carter. 1987. Identification of multiple cell adhesion receptors for collagen and fibronectin in human fibrosarcoma cells processing unique and common $\beta$ subunits. J. Cell Biol. 105:225-231.

10. Takada, Y., E. A. Wayner, W. G. Carter, and M. E. Hemler. 1988. Extracellular matrix receptors, ECMR II and ECMR I, for collagen and fibronectin correspond to VLA-2 and VLA-3 in the VLA family of heterodimers. J. Cell. Biochem. 37:385-393.

11. Pierschbacher, M. D., and E. Ruoslahti. 1984. The cell attachment activity of fibronectin can be duplicated by small synthetic fragments of the molecule. Nature (Lond.). 309:30-33.

12. Hemler, M. E., M. J. Elices, C. Parker, and Y. Takada. 1990. Cell adhesion functions and structural aspects of VLA proteins in the integrin family. J. Cell. Biochem. 14:136a. (Abstr.).

13. Wayner, E. A., A. Garcia-Pardo, M. J. Humphries, J. A. McDonald, and W. G. Carter. 1989. Identification and characterization of the T lymphocyte adhesion receptor for an alternative cell attachment domain (CS-1) in plasma fibronectin. J. Cell Biol. 109:1321-1330.

14. Holzman, B., B. W. McIntyre, and I. L. Weissman. 1989. Identification of a murine Peyer's patch-specific lymphocyte homing receptor as an integrin molecule with an $\alpha$ chain homologous to human VLA-4 $\alpha$. Cell. 56:37-46.

15. Elices, M. J., L. Osborn, Y. Takada, C. Crouse, S. Luhowskyl, M. E. Hemler, and R. R. Lobb. 1990 . VCAM-1 on activated endothelium interacts with the leukocyte integrin VLA-4 at a site distinct from the VLA-4/fibronectin binding site. Cell. 60:577-584.

16. Brown, D. L., D. R. Phillips, C. H. Damsky, and I. F. Charo. 1989. Synthesis and expression of the fibroblast fibronectin receptor in human monocytes. J. Clin. Invest. 84:366-370.

17. Kaufmann, N., D. Frossch, C. Westphal, L. Weber, and E. Klein. 1989. Integrin VLA-3. Ultrastructural localization at cell-cell contact sites on human cell cultures. J. Cell Biol. 109:1807-1815.

18. Hemler, M. E. 1988. Adhesive protein receptors on hematopoietic cells. Immunol. Today. 9:109-113.

19. Coulombel, L., M. H. Vuillet, C. Leroy, and G. Tchernia. 1988. Lineageand stage-specific adhesion of human hematopoietic progenitor cells to extracellular matrices from marrow fibroblasts. Blood. 71:329-334.

20. Patel, V. P., and H. F. Lodish. 1984. Loss of adhesion of murine erythro- 
leukemic cells to fibronectin during erythroid differentiation. Science (Wash. DC). 224:996-998.

21. Tsai, S., V. Patel, E. Beaumont, H. F. Lodish, D. G. Nathan, and C. A. Sieff. 1987. Differential binding of erythroid and myeloid progenitors to fibroblasts and fibronectin. Blood. 69:1587-1594.

22. Vuillet-Gaugler, M. H., J. Breton-Gorius, W. Vainchenker, J. Guichard, C. Leroy, G. Tchernia, and L. Coulombel. 1990. Loss of attachment to fibronectin with terminal erythroid differentiation. Blood. 75:865-873.

23. Edelman, P., G. Vinci, J. L. Villeval, W. Vainchenker, A. Henri, R. Miglierina, R. Rouger, J. Reviron, J. Breton-Gorius, C. Sureau, and L. Edelman. 1986. A monoclonal antibody against an erythrocyte ontogenic antigen identifies fetal and adult erythroid progenitors. Blood. 67:56-63.

24. Kishi, K. 1985. A new leukemia cell line with Philadelphia chromosome characterized as basophil precursors. Leuk. Res. 9:381-390.

25. Nakazawa, M., M. T. Mitjavila, N. Debili, N. Casadevall, P. Mayeux, P. Rouyer-Fessard, A. Dubart, P. H. Romeo, Y. Beuzard, K. Kishi, J. Breton-Gorius, and W. Vainchenker. 1989. A pluripotent human cell line with spontaneous erythroid terminal maturation. Blood. 73:2003-2013.

26. Cardarelli, P. M., and M. D. Pierschbacher. 1987. Identification of the fibronectin receptor on T lymphocytes. J. Cell. Biol. 105:499-506.

27. Sanchez-Madrid, F., M. Cebrian, M. O. De Landazuri, C. Serra, P. Engel, J. Vives, T. Cabrera, A. Sampalo, and F. Garrido. 1989. Report of the IV International Workshop on Leukocyte Differentiation Antigens (Vienna). Immunologia. 8:35-46.

28. Hemler, M. E, F. Sanchez-Madrid, T. J. Flotte, A. M. Krensky, S. J. Burakoff, A. K. Bhan, T. A. Springer, and J. L. Strominger. 1984. Glycoproteins of 210,000 and $130,000 \mathrm{M}$. W. on activated T cells: cell distribution and antigenic relation to components on resting cells and T cell lines. J. Immunol. 132:30113018.

29. Werb, Z., P. M. Tremble, O. Behrendtsen, E. Crowley, and C. H. Damsky. 1989. Signal transduction through the fibronectin receptor induces collagenase and stromelysin gene expression. J. Cell. Biol. 109:877-889.

30. Roman, J., R. M. LaChance, T. J. Brekelman, C. J. Kennedy, E. A. Wayner, W. G. Carter, and J. A. McDonald. 1989. The fibronectin receptor is organized by extracellular matrix fibronectin. Implications for oncogenic transformation and for cell recognition of fibronectin matrices. J. Cell. Biol. 108:2529-2543.

31. Kantor, R. R., M. J. Mattes, K. O. Lloyd, L. J. Lloyd, and A. P. Albino 1987. Biochemical analysis of two cell surface glycoprotein complexes, very common antigen 1 and very common antigen 2. J. Biol. Chem. 262:15158-15165.
32. Wayner, E. A., W. G. Carter, R. S. Piotrowicz, and T. Kunicki. 1988. The function of multiple extracellular matrix receptors in mediating cell adhesion to extracellular matrix: preparation of monoclonal antibodies to the fibronectin receptor that specifically inhibit cell adhesion to fibronectin and react with platelet glycoprotein Ic-IIa. J. Cell. Biol. 107:1881-1891.

33. Kieffer, N., A. Bettaieb, C. Legrand, L. Coulombel, W. Vainchenker, L. Edelman, and J. Breton-Gorius. 1989. Developmentally regulated expression of a $78 \mathrm{kDa}$ erythroblast membrane glycoprotein immunologically related to the platelet thrombospondin receptor. Biochem. J. 262:835-842.

34. Laemmli, U. K. 1970. Cleavage of structural proteins during the assembly of the head of the bacteriophage T4. Nature (Lond.). 227:680-685.

35. Fingerman, E., and M. E. Hemler. 1988. Regulation of proteins in the VLA cell substrate adhesion family. Influence of cell growth conditions on VLA1, VLA-2 and VLA-3 expression. Exp. Cell Res. 177:132-142.

36. Hemler, M. E., C. Huang, and L. Schwarz. 1987. The VLA protein family. Characterization of five distinct cell surface heterodimers each with a common 130,000 molecular weight $\beta$ subunit. J. Biol. Chem. 262:3300-3309.

37. Guan, J. L., and R. O. Hynes. 1990. Lymphoid cells recognize an alternatively spliced segment of fibronectin via the integrin receptor $\alpha 4 \beta 1$. Cell. 60:5361 .

38. Humphries, M. J., A. Komoriya, S. K. Akiyama, K. Olden, and K. M. Yamada. 1987. Identification of two distinct regions of the type III connecting segment of human plasma fibronectin that promote cell type-specific adhesion. $J$. Biol. Chem. 262:6886-6892.

39. Bednarczyk, J. L., and B. W. McIntyre. 1990. A monoclonal antibody to VLA-4 $\alpha$ chain (CDw49d) induces homotypic lymphocyte aggregation. J. Immunol. 144:777-784.

40. Hall, D. E., L. F. Reichardt, E. Crowley, B. Holley, H. Moezzi, A. Sonnenberg, and C. H. Damsky. 1990. The $\alpha 1 / \beta 1$ and $\alpha 6 / \beta 1$ integrin heterodimers mediate cell attachment to distinct sites on laminin. J. Cell Biol. 110:2175-2184.

41. Wayner, E. A., A. Garcia-Pardo, M. J. Humphries, J. A. McDonald, and W. G. Carter. 1989. Identification and characterization of the T lymphocyte adhesion receptor for an alternative cell attachment domain (CS-1) in plasma fibronectin. J. Cell Biol. 109:1321-1330.

42. Mould, A. P., L. A. Wheldon, A. Komoriya, E. A. Wayner, K. M. Yamada, and M. J. Humphries. 1990. Affinity chromatography isolation of the melanoma adhesion receptor for the IIICS region of fibronectin and its identification as the integrin $\alpha 4 \beta 1$. J. Biol. Chem. 265:4020-4024. 